\title{
Diversity of Neopestalotiopsis and Pestalotiopsis spp., Causal Agents of Guava Scab in Colombia
}

Fernando Solarte and Carlos German Muñoz, Universidad Nacional de Colombia-Palmira, Colombia; Sajeewa S. N. Maharachchikumbura, Department of Crop Sciences, College of Agricultural and Marine Sciences, Sultan Qaboos University, Al-Khod 123, Oman; and Elizabeth Álvarez, ${ }^{\dagger}$ International Center for Tropical Agriculture, Palmira, Colombia

\begin{abstract}
Common guava (Psidium guajava L.) is a fruit tree of global economic importance. It is grown in Asia, South and Central America, and Hawaii for its exquisite aroma and flavor, and nutritional and medical properties. However, guava production is limited by guava scab, caused by fungi in the Pestalotiopsis genus. Characteristic symptoms of guava scab are corky, ovoid or round lesions on fruit surfaces. These lesions may thicken, affecting the flesh below and reducing fruit quality and commercial value. We characterized 81 isolates isolated from guava scab lesions on guava leaves and fruit in different regions of Colombia, and identified them as Pestalotiopsis

and Neopestalotiopsis spp. We analyzed the morphology, pathogenicity, and genetic diversity of the isolates based on the sequences of the internal transcribed spacer, $\beta$-tubulin, and elongation factor genes. Isolates were morphologically, pathogenically, and genetically diverse but the diversity did not correlate with geographical origin, or guava cultivar or tissue from which the isolates were recovered. Selected monosporic isolates included in the multiple-gene analysis were identified as belonging to two genera: Neopestalotiopsis (65 isolates with versicolorous conidia) and Pestalotiopsis (4 isolates with concolorous conidia).
\end{abstract}

Guava (Psidium guajava L.) is a small tree that belongs to the genus Psidium (Gutiérrez et al. 2008). The center of origin for guava extends from Mexico to Peru but it is cultivated in most tropical and subtropical countries (Gutiérrez et al. 2008). Guava grows in soils of differing textures, drainage, and $\mathrm{pH}$ (between 4.5 and 9.4). It can grow in regions with high mean annual rainfall or in areas subject to drought (Keith et al. 2006).

In Colombia, guava is usually consumed fresh or processed into a firm, sweet pulp known as bocadillo that is used for juices and jams (Melgarejo et al. 2010). The fruit is a good source of calcium, iron, and phosphorus (Pachanawan et al. 2008). It also provides vitamin A, ascorbic acid (vitamin C), three essential amino acids (tryptophan, lysine, and methionine), and three vitamin B compounds (thiamine or $\mathrm{B} 1$, riboflavin or B2, and niacin or B3) (Gutiérrez et al. 2008). In Colombia, guava production averaged 1.3 million tons per year over the past 5 years (Romero-Frías et al. 2015).

Guava production is socioeconomically important in Colombia, providing more than 4,800 jobs in places such as La Hoya del Río Suárez, Colombia (Rodríguez-Borray and Rangel-Moreno 2005). Guava is an important commodity for domestic markets but also has great export potential. However, guava production is subject to various production constraints, including pests and diseases. Guava scab, also known as pestalotiopsis or nailhead rust, is the most important disease constraint to guava cultivation in Colombia, affecting fruit, leaves, and shoots (Buriticá-Cespedes 1999; Keith et al. 2006). It is caused by a group of fungi in the genus Pestalotiopsis. The first visible symptoms of guava scab are small brown (coffee-bean colored) spots that develop into corky scabs on fruit surfaces. The scabs develop "heads" that resemble oxidized nails. The lesions coalesce to form large lesions that cover part of the fruit and sink into the flesh and, eventually, deform the whole fruit. Leaf symptoms appear as brown lesions that usually show up first on leaf edges and apices. As they expand, lesions become brittle and gray with mycelium growth.

Farfán et al. (2006) reported that Pestalotia spp. are widely distributed throughout La Hoya del Río Suárez, Colombia. They also found

${ }^{\dagger}$ Corresponding author: E. Álvarez; E-mail: e.alvarez@cgiar.org

GenBank accession numbers: KR493520 to KR493741.

Accepted for publication 5 August 2017.

C 2018 The American Phytopathological Society that, in the municipality of Vélez, guava fruit are most susceptible to infection in the transition periods between dry and rainy seasons in March (90.6\%) and between rainy and dry in July (93.1\%), (Farfán et al. 2006). Guava scab has also been reported in Mexico (Morera and Blanco 2009), India, Australia (Jeewon et al. 2003), and the United States (Hawaii) (Keith et al. 2006).

The causal agents of guava scab in Colombia are Pestalotia spp. (Morera and Blanco 2009) and Pestalotiopsis spp. (Keith et al. 2006). However, there have been no efforts to characterize and identify the Pestalotiopsis spp. attacking the guava crop in Colombia. Additionally, the pathogen's distribution in Colombia's principal production areas has not been determined. In general, the guava scab pathogens have been characterized by their morphological features and not by molecular techniques such as multiple-gene analysis. De Notaris (1839) initially described the genus Pestalotia, characterizing it as having a fusiform conidium composed of six cells, and appendages in the apical and basal extremes. Over a century later, Steyaert (1955) divided the genus into three genera according to the number of cells comprising the conidia; specifically, conidia of Pestalotia, Pestalotiopsis, and Truncatella genera possessed six, five, and four cells, respectively. This last classification is still in current use after more than 60 years (Maharachchikumbura et al. 2011). However, the separation of Pestalotiopsis and Pestalotia into distinct genera remained controversial until 1980, when Sutton (1980) used electron microscopy to examine the development of the cell wall in two species of Pestalotiopsis and in Pestalotia pezizoides. Sutton's findings supported Steyaert's classification (Griffiths and Swart 1974a,b).

Until the 1990s, the taxonomy of Pestalotiopsis and related genera was based on describing conidial characteristics because of the stability of their traits. Specifically, the pigmentation of the three medium cells of the conidia are concolorous in Pestalotiopsis and versicolorous in Neopestalotiopsis (Maharachchikumbura et al. 2011, 2012). However, the sole use of conidial characteristics for species identification was controversial because of the wide variability of other morphological characteristics such as colony color, texture, and shape observed for Pestalotiopsis and related genera when grown on culture media (Egger 1995; Hu et al. 2007).

Molecular techniques have become the norm for species differentiation and identification. Maharachchikumbura et al. (2012) evaluated 10 groups of primers, seeking the best regions or genes on which to perform phylogenetic analyses of multiple, replicable, and reliable genes. The authors succeeded in establishing the internal transcribed spacer (ITS) region and the $\beta$-tubulin and translation elongation 1 (tefl) genes as the best regions because of greater amplification 


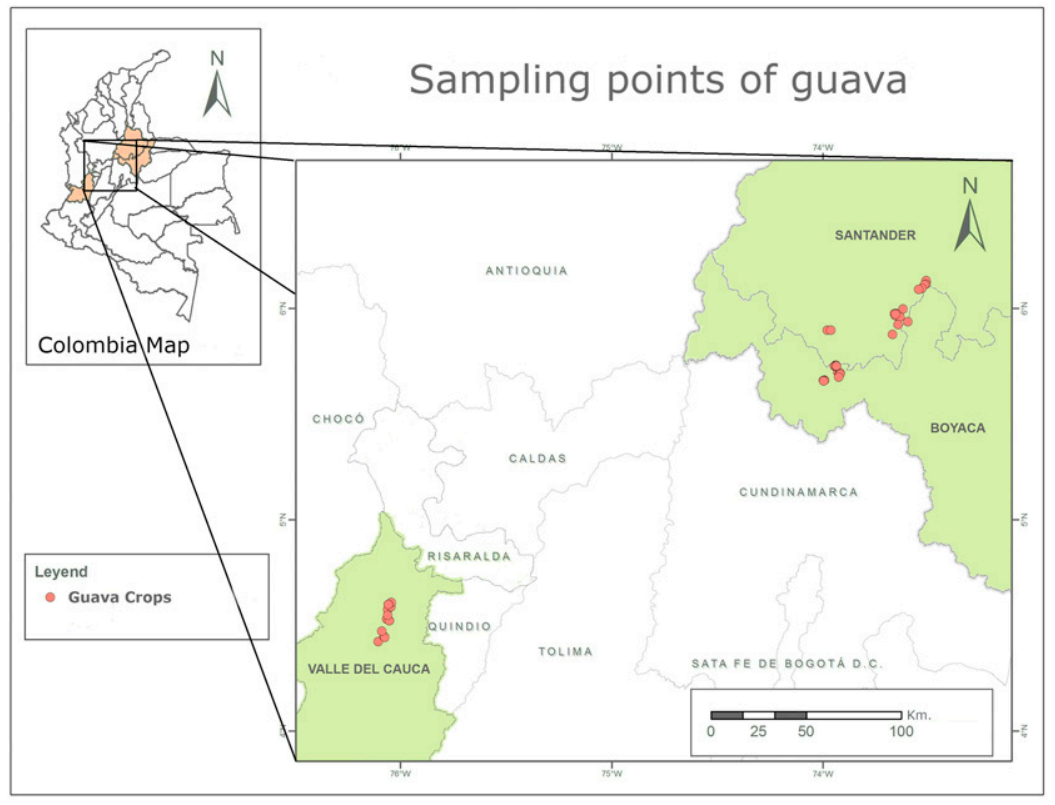

Fig. 1. Sampling areas from which tissues of guava (Psidium guajava L.), infested with scab were obtained.

Table 1. Details of Pestalotiopsis and Neopestalotiopsis isolates obtained from guava fruit and leaves collected from Boyacá, Santander, and Valle del Cauca in Colombia included in this study

\begin{tabular}{|c|c|c|c|c|c|}
\hline Species & Isolate code & Origin & Source & Genotype & Growth rate $(\mathrm{mm})^{\mathbf{z}}$ \\
\hline Neopestalotiopsis & SSbu1 & San Benito, Santander & Fruit & Roja & 16.9 \\
\hline Neopestalotiopsis & SVsnp8 & Vélez, Santander & Leaf & Roja & 16.7 \\
\hline Neopestalotiopsis & VTman1 & Toro, Valle & Fruit & Pera & 16.7 \\
\hline Neopestalotiopsis & VUve3 & La Unión, Valle & Fruit & Pera & 16.5 \\
\hline Neopestalotiopsis & SVsnp3 & Vélez, Santander & Leaf & Roja & 15.6 \\
\hline Neopestalotiopsis & SVpa1 & Vélez, Santander & Leaf & Roja & 15.6 \\
\hline Neopestalotiopsis & BVayr1 & Pauna, Boyacá & Fruit & Roja & 15.4 \\
\hline Neopestalotiopsis & VTman2 & Toro, Valle & Fruit & Pera & 15.3 \\
\hline Neopestalotiopsis & VTman3 & Toro, Valle & Leaf & Pera & 15.3 \\
\hline Neopestalotiopsis & SBma1 & Barbosa, Santander & Fruit & Roja & 15.1 \\
\hline Neopestalotiopsis & SPugra2 & P. Nacional, Santander & Fruit & Roja & 15.1 \\
\hline Neopestalotiopsis & SVpo3 & Vélez, Santander & Fruit & Roja & 15 \\
\hline Neopestalotiopsis & SVsnp11 & Vélez, Santander & Fruit & Roja & 15 \\
\hline Neopestalotiopsis & VUve2 & La Unión, Valle & Fruit & Coronilla & 14.9 \\
\hline Neopestalotiopsis & SBac2 & Barbosa, Santander & Leaf & Roja & 14.9 \\
\hline Neopestalotiopsis & VRes2 & Roldanillo, Valle & Fruit & Manzana & 14.9 \\
\hline Neopestalotiopsis & SPugral & P. Nacional, Santander & Fruit & Roja & 14.8 \\
\hline Neopestalotiopsis & SVpa4 & Vélez, Santander & Fruit & Roja & 14.7 \\
\hline Neopestalotiopsis & SVpo7 & Vélez, Santander & Leaf & Roja & 14.7 \\
\hline Neopestalotiopsis & SPugra5 & P. Nacional, Santander & Fruit & Roja & 14.6 \\
\hline Neopestalotiopsis & BPpa2 & Pauna, Boyacá & Fruit & Roja & 14.5 \\
\hline Neopestalotiopsis & SVpo5 & Vélez, Santander & Leaf & Roja & 14.4 \\
\hline Pestalotiopsis & VTsin3 3 & Toro, Valle & Leaf & Pera & 14.4 \\
\hline Neopestalotiopsis & VRte1 & Roldanillo, Valle & Leaf & Pera & 14.4 \\
\hline Neopestalotiopsis & SSbu2 & San Benito, Santander & Fruit & Roja & 14.1 \\
\hline Neopestalotiopsis & SSre5 & San Benito, Santander & Leaf & Roja & 14.0 \\
\hline Neopestalotiopsis & SVsnp12 & Vélez, Santander & Fruit & Roja & 13.8 \\
\hline Neopestalotiopsis & SVpa3 & Vélez, Santander & Fruit & Roja & 13.7 \\
\hline Neopestalotiopsis & SVsnp2 & Vélez, Santander & Fruit & Roja & 13.7 \\
\hline Neopestalotiopsis & SVsnp7 & Vélez, Santander & Fruit & Roja & 13.7 \\
\hline Neopestalotiopsis & BPva1 & Pauna, Boyacá & Fruit & Roja & 13.6 \\
\hline Neopestalotiopsis & SVsnp1 & Vélez, Santander & Leaf & Roja & 13.6 \\
\hline Neopestalotiopsis & VRes4 & Roldanillo, Valle & Fruit & Manzana & 13.5 \\
\hline Pestalotiopsis & VTman5 & Toro, Valle & Fruit & Pera & 13.5 \\
\hline Neopestalotiopsis & BTca2 & Tununguá, Boyacá & Fruit & Roja & 13.3 \\
\hline Neopestalotiopsis & SVpo2 & Vélez, Santander & Fruit & Roja & 13.3 \\
\hline Neopestalotiopsis & VUgy & La Unión, Valle & Fruit & Pera & 13.2 \\
\hline Neopestalotiopsis & SVsnp9 & Vélez, Santander & Fruit & Roja & 13.1 \\
\hline Pestalotiopsis & VTsin2 & Toro, Valle & Leaf & Pera & 13.1 \\
\hline \multirow[t]{2}{*}{ Neopestalotiopsis } & SVpa8 & Vélez, Santander & Fruit & Roja & 12.9 \\
\hline & & & & & ntinued on next page) \\
\hline
\end{tabular}

${ }_{\mathrm{z}}$ Rate of growth on potato dextrose agar: high $=14.4$ to 16.9 , medium $=12.1$ to 14.1 , and low 5.8 to $11.7 \mathrm{~mm}$. 
through polymerase chain reaction (PCR) and sharper definition of species limits.

Recently, Maharachchikumbura et al. (2014) reclassified Pestalotiopsis into three genera. The sequence analyses of several species based on the large subunit gene, together with the results of the 2012 multiplegene analyses, clearly show three highly diverse lineages. Therefore, two new genera-Neopestalotiopsis and Pseudopestalotiopsis-were introduced. The objective of this study was to characterize and assess the genetic diversity of the isolates causing guava scab in Colombia.

\section{Materials and Methods}

Sampling, isolation, and storage. Samples of infected guava tissues (leaves and fruit) were collected from commercial crops in the Colombian regions of Boyacá, Santander, and Valle del Cauca (Fig. 1). These regions produce different guava varieties with different crop management and edaphoclimatic conditions.

We obtained infected guava leaf and fruit samples $(n=200)$ from 45 farmers' fields. Samples had symptoms that included spots that were blackish gray, necrotic, amorphous, and brittle, and were usually located on leaf apices; or round to oval, brown, corky lesions that were located on the fruit epidermis. The symptomatic guava varieties that were sampled included Palmira ICA-1, Pera, Coronilla, Regional Roja, and Manzana.

Samples $\left(5 \mathrm{~mm}^{2}\right)$ were washed first in deionized water for $10 \mathrm{~min}$, followed by $1 \mathrm{~min}$ in 1\% sodium hypochlorite and $1 \mathrm{~min}$ in $70 \%$ alcohol. Subsequently, samples were washed twice with sterilized distilled water for $1 \mathrm{~min}$. Samples $\left(5 \mathrm{~mm}^{2}\right)$ were then dried on sterilized paper towels, and plated onto potato dextrose agar (PDA; Difco Laboratories
Inc.) modified with $25 \%$ lactic acid at $1 \mathrm{ml} /$ liter (Merck \& Co. Inc.) (five samples per plate). Plates were incubated at $22^{\circ} \mathrm{C} \pm 1$ under $12 \mathrm{~h}$ of light and $12 \mathrm{~h}$ of darkness for 5 days.

To obtain single-spore cultures, we started with 8- to 10-day-old colonies. One acervulus from each colony was picked up using a fine needle and washed into a Petri dish containing water agar with one drop of sterilized distilled water. Drops of water carrying acervuli were then spread over the entire surface of the medium, using a sterilized glass spreader. A stereomicroscope was used to identify one conidium physically separated from the others. A fragment of the culture medium carrying this conidium was transferred to a plate containing fresh PDA medium supplemented with $25 \%$ lactic acid at $1 \mathrm{ml} / \mathrm{liter}$ (Merck \& Co., Inc.). The colonies were incubated at $22^{\circ} \mathrm{C} \pm 1$ under $12 \mathrm{~h}$ of light and $12 \mathrm{~h}$ of darkness for 1 to 2 days.

Morphological characterization. We characterized 81 monoconidial isolates from different acervuli of Pestalotiopsis spp. based on morphological features. From the edges of 5-day-old colonies, discs $(5 \mathrm{~mm}$ in diameter) were transferred to PDA plates and incubated at $22^{\circ} \mathrm{C}$ under $12 \mathrm{~h}$ of light and $12 \mathrm{~h}$ of darkness for 7 days. The morphological characteristics of these cultures were examined 7 days later. Specifically, cultures were examined for colony color, growth rate, presence or absence of acervuli, conidia length and width, apical and basal appendage length, and other characteristics, as described by Keith et al. (2006) and Maharachchikumbura et al. (2011). To determine the growth rate, isolates were cultured in 90-mm Petri dishes containing PDA in a randomized complete block design with three replications. The experiment was repeated twice. Disks ( $5 \mathrm{~mm}$ in diameter) were cut from the edge of a 5-day-old colony and placed in the center of Petri dishes with

Table 1. (Continued from previous page)

\begin{tabular}{|c|c|c|c|c|c|}
\hline Species & Isolate code & Origin & Source & Genotype & Growth rate $(\mathrm{mm})^{\mathrm{z}}$ \\
\hline Neopestalotiopsis & VUve1 & La Unión, Valle & Fruit & Pera & 12.8 \\
\hline Neopestalotiopsis & BPca2 & Pauna, Boyacá & Fruit & Roja & 12.7 \\
\hline Neopestalotiopsis & SSre3 & San Benito, Santander & Leaf & Roja & 12.7 \\
\hline Neopestalotiopsis & SSbu3 & San Benito, Santander & Fruit & Roja & 12.7 \\
\hline Neopestalotiopsis & SSre2 & San Benito, Santander & Leaf & Roja & 12.7 \\
\hline Neopestalotiopsis & VUgu1 & La Unión, Valle & Fruit & Pera & 12.6 \\
\hline Neopestalotiopsis & SVpo1 & Vélez, Santander & Fruit & Roja & 12.5 \\
\hline Neopestalotiopsis & SVsnp13 & Vélez, Santander & Fruit & Roja & 12.5 \\
\hline Neopestalotiopsis & VTman6 & Toro, Valle & Leaf & Pera & 12.5 \\
\hline Neopestalotiopsis & SVpo6 & Vélez, Santander & Fruit & Roja & 12.3 \\
\hline Neopestalotiopsis & SVsnp6 & Vélez, Santander & Fruit & Roja & 12.3 \\
\hline Neopestalotiopsis & VTsin 1 & Toro, Valle & Leaf & Pera & 12.2 \\
\hline Neopestalotiopsis & SVpa7 & Vélez, Santander & Fruit & Roja & 12.2 \\
\hline Neopestalotiopsis & SVsnp5 & Vélez, Santander & Leaf & Roja & 12.1 \\
\hline Neopestalotiopsis & SVpo2-2 & Vélez, Santander & Fruit & Roja & 12.1 \\
\hline Neopestalotiopsis & BPcal & Pauna, Boyacá & Fruit & Roja & 11.7 \\
\hline Neopestalotiopsis & SVpa6 & Vélez, Santander & Fruit & Roja & 11.7 \\
\hline Neopestalotiopsis & SBac1 & Barbosa, Santander & Leaf & Roja & 11.7 \\
\hline Neopestalotiopsis & SBma3 & Barbosa, Santander & Fruit & Roja & 11.6 \\
\hline Pestalotiopsis & SSpla & San Benito, Santander & Fruit & Roja & 11.6 \\
\hline Neopestalotiopsis & VRes1 & Roldanillo, Valle & Fruit & Manzana & 11.5 \\
\hline Neopestalotiopsis & VUve4 & La Unión, Valle & Fruit & Pera & 11.5 \\
\hline Neopestalotiopsis & SVpa5 & Vélez, Santander & Fruit & Roja & 11.5 \\
\hline Neopestalotiopsis & SPugra4 & P. Nacional, Santander & Fruit & Roja & 11.3 \\
\hline Neopestalotiopsis & VUgu2 & La Unión, Valle & Fruit & Pera & 11.1 \\
\hline Neopestalotiopsis & SPugra3 & P. Nacional, Santander & Fruit & Roja & 11 \\
\hline Neopestalotiopsis & SVpo4 & Vélez, Santander & Fruit & Roja & 11 \\
\hline Neopestalotiopsis & BTcal & Tununguá, Boyacá & Fruit & Roja & 11 \\
\hline Neopestalotiopsis & VRes3 & Roldanillo, Valle & Fruit & Manzana & 10.8 \\
\hline Neopestalotiopsis & VRlep & Roldanillo, Valle & Fruit & Pera & 10.8 \\
\hline Pestalotiopsis & SVsnp4 & Vélez, Santander & Fruit & Roja & 10.5 \\
\hline Neopestalotiopsis & BPpa1 & Pauna, Boyacá & Fruit & Roja & 9.7 \\
\hline Neopestalotiopsis & SVsnp10 & Vélez, Santander & Leaf & Roja & 8.9 \\
\hline Neopestalotiopsis & VTman4 & Toro, Valle & Leaf & Pera & 8.5 \\
\hline Neopestalotiopsis & SBma2 & Barbosa, Santander & Fruit & Roja & 8.4 \\
\hline Neopestalotiopsis & BVayr2 & Pauna, Boyacá & Fruit & Roja & 8.3 \\
\hline Neopestalotiopsis & VTpo & Roldanillo, Valle & Fruit & Pera & 8.1 \\
\hline Neopestalotiopsis & SVpa2 & Vélez, Santander & Fruit & Roja & 8.1 \\
\hline Neopestalotiopsis & SSre4 & San Benito, Santander & Fruit & Roja & 7.9 \\
\hline Neopestalotiopsis & VUgu3 & La Unión, Valle & Fruit & Pera & 7.2 \\
\hline Neopestalotiopsis & SSre1 & San Benito, Santander & Leaf & Roja & 5.8 \\
\hline
\end{tabular}



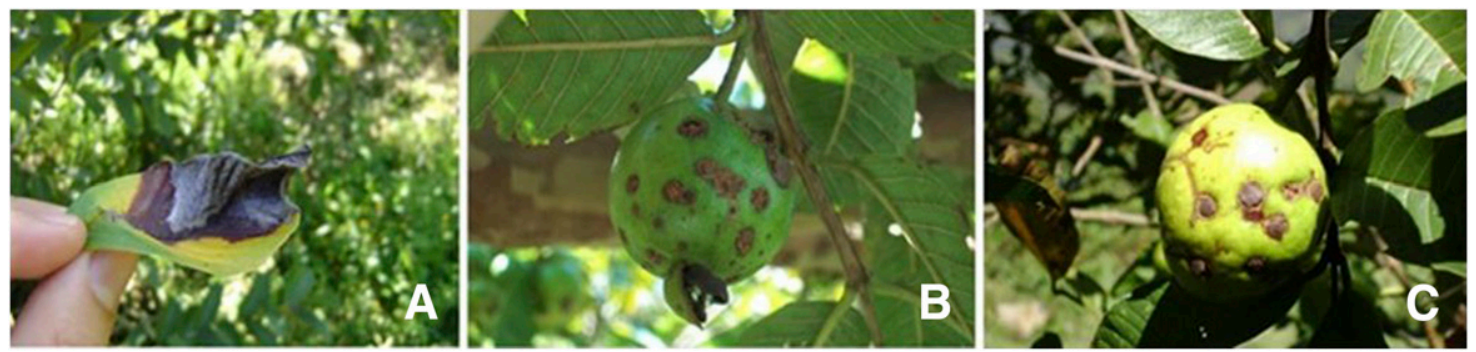

Fig. 2. Symptoms of guava scab on A, leaf, B, immature fruit, and C, mature fruit.

Table 2. Details of isolates representing species in the phylogenetic clades of Pestalotiopsis and Neopestalotiopsis used in this study

\begin{tabular}{|c|c|c|c|}
\hline Species & GenBank accession number ${ }^{\mathbf{z}}$ & Host, substrate & Location \\
\hline Neopestalotiopsis aotearoa & CBS 367.54; ATCC 11763; QM 381 & Canvas & New Zealand \\
\hline N. asiatica & MFLUCC 12-0286; NN0476380 & Unidentified tree & China \\
\hline N. australis & CBS 114159; STE-U 3017 & Telopea sp. & Australia \\
\hline N. chrysea & MFLUCC 12-0261; NN042855 & Dead leaves & China \\
\hline N. chrysea & MFLUCC 12-0262; NN047037 & Dead plant & China \\
\hline N. clavispora & CBS 447.73 & Decaying wood & Sri Lanka \\
\hline N. clavispora & MFLUCC 12-0280; NN043011 & Magnolia sp. & China \\
\hline N. clavispora & MFLUCC 12-0281; NN043133 & Magnolia sp. & China \\
\hline N. cubana & CBS 600.96; INIFAT C96/44-4 & Leaf litter & Cuba \\
\hline N. ellipsospora & CBS 115113; HKUCC 9136 & Ardisia crenata & Hong Kong \\
\hline N. ellipsospora & MFLUCC 12-0283 & Dead plant materials & China \\
\hline N. eucalypticola & CBS 264.37; BBA 5300 & Eucalyptus globulus & $\ldots$ \\
\hline N. egyptiaca & CBS 140162 & Mangifera indica & Egypt \\
\hline N. foedans & CGMCC 3.9123 & Mangrove plant & China \\
\hline N. foedans & CGMCC 3.9178 & Neodypsis decaryi & China \\
\hline N. foedans & CGMCC 3.9202 & Calliandra hematocephala & China \\
\hline N. formicarum & CBS 115.83 & Plant debris & Cuba \\
\hline N. formicarum & CBS 362.72 & Dead Formicidae (ant) & Ghana \\
\hline N. honoluluana & CBS 111535; STE-U 2078 & Telopea sp. & United States: Hawaii \\
\hline N. honoluluana & CBS 114495; STE-U 2076 & Telopea sp. & United States: Hawaii \\
\hline N. iraniensis & CBS 137768 & Fragaria $\times$ ananassa & Iran \\
\hline N. javaensis & CBS 257.31 & Cocos nucifera & Indonesia: Java \\
\hline N. magna & MFLUCC 12-652; ICMP 20011 & Pteridium sp. & France \\
\hline N. mesopotamica & CBS 299.74 & Eucalyptus sp. & Turkey \\
\hline N. mesopotamica & CBS 336.86 & Pinus brutia & Iraq \\
\hline N. natalensis & CBS 138.41 & Acacia mollissima & South Africa \\
\hline N. piceana & CBS 225.30 & Mangifera indica & $\ldots$ \\
\hline N. piceana & CBS 254.32 & Cocos nucifera & Indonesia: Sulawesi \\
\hline N. piceana & CBS 394.48 & Picea sp. & United Kingdom \\
\hline N. protearum & CBS 114178; STE-U 1765* & Leucospermum cuneiforme & Zimbabwe \\
\hline N. rosae & CBS 101057 & Rosa sp. & New Zealand \\
\hline N. rosae & CBS 124745 & Paeonia suffruticosa & United States \\
\hline N. samarangensis & CBS 115451; HKUCC 9095 & Unidentified tree & Hong Kong \\
\hline N. saprophytica & CBS 115452; HKUCC 8684 & Litsea rotundifolia & Hong Kong \\
\hline Neopestalotiopsis sp. & CBS 233.79 & Crotalaria juncea & India \\
\hline Neopestalotiopsis sp. & CBS 110.20 & $\ldots$ & $\ldots$ \\
\hline Neopestalotiopsis sp. & CBS 177.25 & Dalbergia sp. & $\ldots$ \\
\hline Neopestalotiopsis sp. & CBS 274.29 & Cocos nucifera & Indonesia: Java \\
\hline Neopestalotiopsis sp. & CBS 322.76 & Camellia sp. & France \\
\hline Neopestalotiopsis sp. & CBS 664.94 & Cocos nucifera & Netherlands \\
\hline Neopestalotiopsis sp. & CBS 164.42 & Dune sand & France \\
\hline Neopestalotiopsis sp. & CBS 360.61 & Cinchona sp. & Guinea \\
\hline Neopestalotiopsis sp. & CBS 119.75 & Achras sapota & India \\
\hline Neopestalotiopsis sp. & CBS 266.80 & Vitis vinifera & India \\
\hline Neopestalotiopsis sp. & CBS 266.37; BBA 5087; IMI 083708 & Erica sp. & Germany \\
\hline \multirow[t]{2}{*}{ Neopestalotiopsis sp. } & CBS 323.76 & Erica gracilis & France \\
\hline & & & (Continued on next page) \\
\hline
\end{tabular}

y Phylogenetic clades of genus Pestalotiopsis and Neopestalotiopsis as described by Maharachchikumbura et al. (2014), Ariyawansa et al. (2015), Liu et al. (2015), and Jayawardena et al. (2016).

${ }^{\mathrm{z}} \mathrm{CBS}=$ culture collection of the Centralbureau voor Schimmelcultures, Fungal Biodiversity Centre, Utrecht, The Netherlands; CGMCC $=$ China General Microbiological Culture Collection Center, Institute of Microbiology, Chinese Academy of Sciences, Beijing; ICMP = International Collection of Microorganisms from Plants, Auckland, New Zealand; IFRDCC = International Fungal Research \& Development Centre Culture Collection, China; MFLUCC = Mae Fah Luang University Culture Collection, Chiang Rai, Thailand; and IMI = International Mycological Institute, England. 
mycelium in direct contact with PDA medium. The isolates were incubated at $22^{\circ} \mathrm{C}$ under $12 \mathrm{~h}$ of light and $12 \mathrm{~h}$ of darkness for 7 days and radial growth was measured daily. Analysis of variance (ANOVA) of characteristics described above was carried out with the Statistical Analysis System (SAS software, v. 9.0) $(P<0.01)$, and the Ryan-EinotGabriel-Welsch (REGW) multiple-range test was used to separate means $(\alpha=0.05)$.

To determine the average length, width, and number of appendages of conidia, 20 mature conidia were obtained from each 10-day-old isolate. Conidia were mounted on slides and stained with cotton blue for contrast. Photographs were taken with a Leica microscope at $\times 400$ magnification and measurements were made using the ImageJ software (Image Processing and Analysis in Java). The 20 measurements were subjected to an ANOVA with 20 replications using SAS v. 9.0 software and the REGW multiple-range test to separate means $(\alpha=0.05)$.

Pathogenicity tests. The aggressiveness of the 81 isolates was evaluated by inoculating them onto detached, physiologically mature guava fruit (variety Palmira ICA-1). The fruit were disinfected by immersion into $2 \%$ sodium hypochlorite for $2 \mathrm{~min}$, then $70 \%$ alcohol for $1 \mathrm{~min}$, and finally rinsing twice in sterilized distilled water for $1 \mathrm{~min}$ each time. Fruit were air dried on sterilized paper towels in a laminar flow chamber for $30 \mathrm{~min}$.

The fruit were inoculated as follows: a 5-mm disc of PDA medium with mycelia from a 5-day-old culture was placed on a $1.5-\mathrm{mm}$ wound made by removing a piece of fruit epidermis. The disc was

Table 2. (Continued from previous page)

\begin{tabular}{|c|c|c|c|}
\hline Species & GenBank accession number ${ }^{\mathrm{z}}$ & Host, substrate & Location \\
\hline Neopestalotiopsis sp. & CBS 361.61 & Cissus sp. & Netherlands \\
\hline N. steyaertii & IMI 192475 & Eucalyptus viminalis & Australia \\
\hline N. surinamensis & CBS 111494; STE-U 1779 & Protea eximia & Zimbabwe \\
\hline N. umbrinospora & MFLUCC 12-0285; NN042986 & Unidentified plant & China \\
\hline N. vitis & MFLUCC 15-1265 & Vitis vinifera & China \\
\hline N. zimbabwana & CBS 111495; STE-U 1777 & Leucospermum cunciforme & Zimbabwe \\
\hline Pestalotiopsis adusta & ICMP 6088 & On refrigerator door $\mathrm{PVC}$ gasket & Fiji \\
\hline P. anacardiacearum & IFRDCC 2397 & Mangifera indica & China \\
\hline P. arceuthobii & CBS 434.65 & Arceuthobium campylopodum & United States \\
\hline P. arengae & CBS 331.92 & Arenga undulatifolia & Singapore \\
\hline P. australasiae & CBS 114126; STE-U 2896 & Knightia sp. & New Zealand \\
\hline P. australis & CBS 111503; STE-U 1770 & Protea neriifolia $\times$ susannae & South Africa \\
\hline P. biciliata & CBS 124463 & Platanus $\times$ hispanica & Slovakia \\
\hline P. biciliata & CBS 236.38 & Paeonia sp. & Proteaceae \\
\hline P. biciliata & CBS 790.68 & Taxus baccata & Taxaceae \\
\hline P. brassicae & CBS 170.26 & Brassica napus & New Zealand \\
\hline P. camelliae & CBS 443.62 & Camellia sinensis & Turkey \\
\hline P. chamaeropis & CBS 113604; STE-U 3078 & $\ldots$ & $\ldots$ \\
\hline P. clavata & MFLUCC 12-0268; NN0471340 & Buxus sp. & China \\
\hline P. colombiensis & CBS 118553; CPC 10969 & Eucalyptus eurograndis & Colombia \\
\hline P. diploclisiae & CBS 115449; HKUCC 9103 & Psychotria tutcheri & Hong Kong \\
\hline P. diversiseta & MFLUCC 12-0287; NN0472610 & Rhododendron sp. & China \\
\hline P. ericacearum & IFRDCC 2439 & Rhododendron delavayi & China \\
\hline P. furcata & MFLUCC 12-0054; CPC 20280 & Camellia sinensis & Thailand \\
\hline P. gaultheria & IFRD 411-014 & Gaultheria forrestii & China \\
\hline P. grevilleae & CBS 114127; STE-U 2919 & Grevillea sp. & Australia \\
\hline P. hawaiiensis & CBS 114491; STE-U 2215 & Leucospermum sp. & United States: Hawaii \\
\hline P. hollandica & CBS 265.33 & Sciadopitys verticillata & Netherlands \\
\hline P. humus & CBS 115450; HKUCC 9100 & Ilex cinerea & Hong Kong \\
\hline P. inflexa & MFLUCC 12-0270; NN0470980 & Unidentified tree & China \\
\hline P. intermedia & MFLUCC 12-0259; NN0476420 & Unidentified tree & China \\
\hline P. jesteri & CBS $109350=$ MONT 6M-B-3 & Fragraea bodenii & Papua New Guinea \\
\hline P. kenyana & CBS 442.67 & Coffea sp. & Kenya \\
\hline P. knightiae & CBS 111963; STE-U 2905 & Knightia sp. & New Zealand \\
\hline P. linearis & MFLUCC 12-0271; NN0471900 & Trachelospermum sp. & China \\
\hline P. malayana & CBS 102220 & Macaranga triloba & Malaysia \\
\hline P. monochaeta & CBS 144.97 & Quercus robur & Netherlands \\
\hline P. montelica & MFLUCC12-0279 & $\ldots$ & Thailand \\
\hline P. novae-hollandiae & CBS 130973 & Banksia grandis & Australia \\
\hline P. oryzae & CBS 111522; STE-U 2083 & Telopea sp. & United States: Hawaii \\
\hline P. papuana & CBS 331.96 & Coastal soil & Papua New Guinea \\
\hline P. parva & CBS 265.37; BBA 2820 & Delonix regia & $\ldots$ \\
\hline P. portugalica & CBS 393.48 & $\ldots$ & Portugal \\
\hline P. rhododendri & IFRDCC 2399 & Rhododendron sinogrande & China \\
\hline P. rosea & MFLUCC 12-0258; NN0471350 & Pinus sp. & China \\
\hline P. shorea & MFLUCC12-0314 & Shorea obtusa & Thailand \\
\hline P. scoparia & CBS 176.25 & Chamaecyparis sp. & $\ldots$ \\
\hline P. spathulata & CBS 356.86 & Gevuina avellana & Chile \\
\hline P. telopeae & CBS 113606; STE-U 3082 & Telopea sp. & Australia \\
\hline P. trachicarpicola & IFRDCC 2403 & Podocarpus macrophyllus & China \\
\hline P. unicolor & MFLUCC 12-0275; NN0473080 & Unidentified tree & China \\
\hline P. verruculosa & MFLUCC 12-0274; NN0473090 & Rhododendron sp. & China \\
\hline
\end{tabular}


then covered with the piece of epidermis and sealed with parafilm. Fruit were placed on a plastic grate inside translucent polypropylene boxes. Water was added to a level below the plastic grate to maintain $100 \%$ relative humidity. The boxes were then hermetically sealed and incubated at $22^{\circ} \mathrm{C}$ under $12 \mathrm{~h}$ of light and $12 \mathrm{~h}$ of darkness for 12 days.

Aggressiveness was evaluated as "lesion diameter" (mean diameter of three lesions per day) at 4, 8, and 12 days after inoculation. Each isolate was replicated three times and the experiment was conducted twice. Fruit inoculated in a similar manner with PDA discs with no mycelia served as negative controls. Data were analyzed by ANOVA $(P<$ 0.01 ), and mean separation tests were conducted using the REGW multiple-range test $(\alpha=0.05)$, using SAS v. 9.0 software.

Phylogenetic analysis of multiple genes. DNA extraction. To extract DNA, we used the methodology reported by Gramaje et al. (2009). Fragments of 5-day-old fungal mycelium grown on PDA were transferred to $1.5-\mathrm{ml}$ Eppendorf tubes, each containing $200 \mu \mathrm{l}$ of cetyltrimethylammonium bromide (CTAB) extraction buffer $(0.2 \mathrm{M}$ Tris, $1.4 \mathrm{M} \mathrm{NaCl}, 20 \mathrm{mM}$ EDTA, and of CTAB at $0.2 \mathrm{~g} /$ liter). The mycelium was macerated in $600 \mu \mathrm{l}$ of buffer using a sterilized micropestle (Sigma-Aldrich), until pulverized. The tubes were then incubated at $65^{\circ} \mathrm{C}$ for $15 \mathrm{~min}$, after which $400 \mu l$ of chloroform-isoamyl alcohol (24:1) was added to each tube. Tubes were mixed by inverting and immediately centrifuged at $15,800 \times g$ for $5 \mathrm{~min}$.

The supernatant (approximately $500 \mu \mathrm{l}$ ) was transferred to a fresh tube and $600 \mu \mathrm{l}$ of cold isopropanol and $166 \mu \mathrm{l}$ of cold $7.5 \mathrm{M}$ ammonium acetate were added to obtain a final concentration of $2.5 \mathrm{M}$. The tubes were then incubated at room temperature for $15 \mathrm{~min}$ and centrifuged at $15,800 \times g$ for $5 \mathrm{~min}$. The supernatant was discarded, saving only the pellets. Cold $70 \%$ ethanol $(1 \mathrm{ml})$ was added to each tube and centrifuged at $15,800 \times g$ for $5 \mathrm{~min}$. The supernatant was discarded and the pellet was dried in a SpeedVac dryer at $37^{\circ} \mathrm{C}$ for $50 \mathrm{~min}$. After drying, the pellets were resuspended in Tris-EDTA buffer and $1.5 \mu \mathrm{l}$ of RNase was added to each tube. Tubes were incubated at $37^{\circ} \mathrm{C}$ for $30 \mathrm{~min}$.

Amplification of the ITS, $\beta$-tubulin, and tefl genes. The PCR assay was used to amplify the ITS region and the $\beta$-tubulin and tefl genes. The three regions were amplified using primers and amplification conditions that were previously described (Glass and Donaldson 1995; Maharachchikumbura et al. 2012; Rehner 2001; White et al. $1990)$. For the PCR amplifications, a $25-\mu 1$ reaction volume was prepared, consisting of $10 \mathrm{ng}$ of DNA, a final $1 \times$ concentration of Promega GoTaq Green Master Mix 2X, and $0.5 \mathrm{mM}$ each primer. The reactions were carried out in a PTC-100 thermal cycler (MJ Research Inc.).

The PCR products were first cleaned by adding $25 \mu$ l of polyethylene glycol (20\%) and $\mathrm{NaCl}(2.5 \mathrm{M})$ solution to each sample. The mixture was homogenized using a vortexer (Scientific Industries) and incubated at room temperature for $15 \mathrm{~min}$. The solution was centrifuged at 13,000 rpm for $15 \mathrm{~min}$, and the supernatant was discarded. Then, $70 \%$ ethanol $(100 \mu \mathrm{l})$ was added to the tube and the solution was centrifuged at 13,000 rpm for $3 \mathrm{~min}$. The ethanol was carefully removed and each pellet was dried by incubation at $38^{\circ} \mathrm{C}$ for $30 \mathrm{~min}$. Finally, each DNA pellet was resuspended in $20 \mu \mathrm{l}$ of ultrapure distilled water (Invitrogen). The amplicons were sent to the DNA Facility of the Iowa State University, Ames, for sequencing. The sequences were aligned to obtain a consensus sequence of the amplified regions for all isolates. This sequence was analyzed using ChromasPro (version 1.49 beta) and MEGA 5.2 (Kumar et al. 2012). Homologies were sought using the BLAST tool in GenBank. The reference sequences were downloaded from GenBank species type (holotype, epitype, and ex-epitype) and others previously referred to by Maharachchikumbura et al. (2014), Ariyawansa et al. (2015), Liu et al. (2015), and Jayawardena et al. (2016) (Table 1). These sequences were aligned with the sequences obtained from the isolates collected from guava using MEGA 5.2. The aligned sequences were analyzed using Bayesian Inference of Phylogeny, variant Metropolis coupled Markov Chain Monte Carlo, and MrBayes software 3.2.1 (http://mrbayes.sourceforge.net/download.php) (Ronquist et al. 2012). The best model for substituting nucleotides for the sequences of each primer was determined separately, using the application jModelTest 2.1.4 (http://darwin.uvigo.es/our-software/) (Posada 2008). For the multilocus analysis of the combined ITS region, $\beta$-tubulin, and tefl genetic loci, 30 million generations were run, sampling every 1,000 generations and omitting the first $25 \%$ of trees generated. From the remaining trees sampled, the consensus tree was estimated at a domain of more than 50\%. The resulting trees were printed with Fig Tree, version 1.4.0 (http:// tree.bio.ed.ac.uk/software/figtree/), and the layout was made with Adobe Illustrator Cs (V.6).

\section{Results}

Isolating the fungi. We collected 81 isolates from the three regions sampled as follows. We recovered 76 Neopestalotiopsis isolates, with 9 coming from Boyacá, 44 from Santander, and 23 from Valle del Cauca. We also recovered five Pestalotiopsis isolates, with three from Santander and two from Valle del Cauca. We isolated Neopestalotiopsis spp. from fruit in all phenological stages of development and from mature leaves, whereas Pestalotiopsis spp. were isolated only from fruit (Fig. 2). Neopestalotiopsis isolates came from tissues of productive trees of the four most common varieties (Pera, Manzana, Coronilla, and Regional Roja) found in the sampling zones. In contrast, Pestalotiopsis isolates were found only on Regional Roja and Pera.

Morphological characterization-Macroscopic. No morphological differences were found between Pestalotiopsis and Neopestalotiopsis isolates. The 81 isolates grouped into morphotypes 1 through 9 according to colony characteristics (Table 1). The principal descriptors were surface color, texture, mycelium production (high, medium, or low), presence or absence of surface acervuli, and edge type. However, surface color, mycelium production, and texture were given the most weight because the other characteristics were highly variable. The 81 isolates were distributed throughout the 9 morphotypes as follows: $1=33(40.7 \%) ; 2=16(19.7 \%) ; 7=6$ $(7.4 \%) ; 3,4,5$, and $9=5(6.17 \%)$ each; $8=4(4.9 \%)$; and $6=1(1.2 \%)$.

In all, $24(30 \%)$ isolates had a high growth rate on artificial culture media, while $31(38 \%)$ grew at medium rates. The remaining 26 $(32 \%)$ isolates grew slowly (Table 2). Moreover, no correlation was found between growth rate on artificial culture medium and colony morphology.

Morphological characterization-Microscopic. Microscopic characterization was carried out on 48 isolates that produced fruiting bodies with conidia. Sporulation was low in the remaining 33 isolates. On subculturing, these isolates lost morphological characteristics, including the ability to produce fruiting bodies.

The minimum and maximum values for conidium length were 19.05 and $29.25 \mu \mathrm{m}$, respectively, while the minimum and maximum values for conidium width were 4.40 and $10.40 \mu \mathrm{m}$, respectively. The averages ranged from 21.38 to $25.74 \mu \mathrm{m}$ for length and 5.13 to $8.34 \mu \mathrm{m}$ for width.

The minimum and maximum values for length of apical appendages were 11.54 and $34.8 \mu \mathrm{m}$, respectively, and the minimum and maximum values for length of basal appendages were 3.00 and $6.75 \mu \mathrm{m}$, respectively. For most isolates, appendage number per conidium was constant, with most isolates presenting conidia with three apical and one basal appendages (Table 3).

Of the 48 isolates, 46 were Neopestalotiopsis spp. Analysis of their median cells showed that they had versicolored conidia, with two upper median cells being darker than the lowest median cell. Of these isolates, 45 had dark and pale coffee-colored conidia and 1 (Vr1eP) presented blackish-gray conidia. The two remaining isolates (VTman5 and SSpla) were Pestalotiopsis spp. and had concolorous conidia (Fig. 3).

The posthoc test used in ANOVA on conidial length and width data showed significant differences $(P=0.05)$ only for isolates VTman5 and SSpla, which formed one group, and for isolate Vr1eP, which formed another group by itself. The characteristics shared by all other isolates were not significantly different. Isolates VTman5 and SSpla also stood out for their long and thin conidia, which were 5.42 and $5.13 \mu \mathrm{m}$ wide, respectively. Their length-to-width ratio was also the highest and, although Vr1eP had a similar length-to-width ratio, it had a higher average width $(5.94 \mu \mathrm{m})$. 
Pathogenicity tests. Isolates that did not form lesions were considered nonpathogenic, and did not differ significantly from the control. Of the 81 isolates, 4 were not pathogenic. Different degrees of aggressiveness were observed among the 77 pathogenic isolates by means of two variables: diameter of the lesion (DL) and area under the disease-progress curve. SAS cluster analysis (Ward's Minimum Variance Cluster Analysis) separated the isolates into three groups according to their level of aggressiveness $(P=0.05)$ : low, intermediate, and high.

The ANOVA $(P<0.01)$ for variable DL showed significant differences for aggressiveness, according to the REGW multiple-range test $(\alpha=0.05)$. The high aggressiveness group was composed of Neopestalotiopsis isolates, mainly from Santander and Valle del Cauca and one (BVayr1) from Boyacá. The most aggressive isolate was SVpo5 from Vélez (Santander), standing out from all the others, including the highly aggressive VRes2, SVpa1, BVayr1, SVsnp8, and VRte1.

Fruit attacked by mildly aggressive isolates developed small lesions with few visible acervuli on their surfaces. Intermediately aggressive isolates usually produced a larger quantity of surface acervuli but small quantities of mycelia. Highly aggressive isolates produced large quantities of mycelia and surface acervuli by 12 days after inoculation.

Molecular characterization. Phylogenetic analysis. The phylogenetic analysis included reference sequences from 52 Pestalotiopsis and 27 Neopestalotiopsis spp., all 79 epitypified, and 13 Neopestalotiopsis spp. published by Maharachchikumbura et al. (2014), Ariyawansa et al. (2015), Liu et al. (2015), and Jayawardena et al. (2016). The sequences from this study are available in GenBank as accession numbers KR493595 to KR493664.

Sequence analysis enabled the separation of isolates into two genera: Pestalotiopsis (Fig. 4) and Neopestalotiopsis (Fig. 5). Moreover, this analysis enabled us to establish that, under our study's conditions, the Neopestalotiopsis isolates were more numerous $(n=63)$ than the Pestalotiopsis isolates $(n=4)$. Therefore, the phylogenetic analysis presents them in separate cladograms.

The four Pestalotiopsis are grouped into two clades (Fig. 4); the first two (VTsin2 and SSpla) formed one clade, Pestalotiopsis sp. 1, and the other two isolates (SVsnp4 and VTman5) formed a separate clade with Pestalotiopsis australasiae.

For the Neopestalotiopsis group (Fig. 5), the 63 isolates in this study were distributed across 11 well-defined clades. Of the 63 isolates, 40 were grouped into two clades, Neopestalotiopsis sp. 1 and Neopestalotiopsis sp. 3, with no reference sequences being present. Clade Neopestalotiopsis sp. 1 was more homogeneous.

Some sequences of Neopestalotiopsis spp. were closely related to reference species. For example, BVayr1 and SPugra5 formed a clade with Neopestalotiopsis surinamensis. Likewise, VR1ep formed a

Table 3. Morphological, cultural, and pathogenic characteristics of 65 Neopestalotiopsis and 4 Pestalotiopsis isolates obtained from guava and grouped according to genetic diversity clusters, as identified through multilocus analysis

\begin{tabular}{|c|c|c|c|c|c|c|c|c|c|}
\hline \multirow[b]{2}{*}{ Clade $^{u}$} & \multirow[b]{2}{*}{ Tissuev $^{v}$} & \multirow[b]{2}{*}{ Type $^{w}$} & \multirow[b]{2}{*}{ Genus, species } & \multirow[b]{2}{*}{ Origin } & \multicolumn{2}{|c|}{$\begin{array}{l}\text { Conidium } \\
\text { size }(\mu \mathrm{m})^{t}\end{array}$} & \multirow[b]{2}{*}{$\mathbf{L} / \mathbf{W}^{\mathbf{x}}$} & \multirow[b]{2}{*}{ AUDPC $^{\mathbf{y}}$} & \multirow[b]{2}{*}{ Growth $^{\mathrm{z}}$} \\
\hline & & & & & $\mathbf{L}$ & $\mathbf{W}$ & & & \\
\hline $1 \mathrm{p}(2)$ & Fruit & 1 & Pestalotiopsis & Santander, Valle del Cauca & 24.7 & 5.4 & $4.5 \mathrm{a}$ & $27.7(36.6-18.8) \mathrm{ab}$ & 11.9 \\
\hline $2 \mathrm{p}(2)$ & Fruit, leaf & 1,5 & Pestalotiopsis australasiae & Santander, Valle del Cauca & 22.9 & 5.1 & $4.4 \mathrm{a}$ & $28.6(36.5-20.7) \mathrm{ab}$ & 12.3 \\
\hline $1(19)$ & Fruit, leaf & $1,2,3,4,5,7,8,9$ & Neopestalotiopsis & Santander, Valle del Cauca & 23.5 & 6.6 & $3.5 \mathrm{~cd}$ & $27.5(7.5-75.7) \mathrm{abc}$ & 12.7 \\
\hline $2(3)$ & Fruit & 1,3 & Neopestalotiopsis & Boyacá & 23.1 & 6.2 & $3.7 \mathrm{~cd}$ & $31.6(24.9-39.4) \mathrm{b}$ & 15.3 \\
\hline $3(21)$ & Fruit, leaf & $1,2,3,4,5,6,7,8,9$ & Neopestalotiopsis & Boyacá, Santander, Valle del Cauca & 23.4 & 7.1 & 3.2 ef & $38.1(0-99.2) \mathrm{abc}$ & 13.5 \\
\hline $4(2)$ & Fruit & 1,2 & Neopestalotiopsis surinamensis & Boyacá, Santander & 22.7 & 6.6 & $3.4 \mathrm{de}$ & $62.6(58.8-66.4) \mathrm{a}$ & 15.0 \\
\hline $5(8)$ & Fruit & $1,2,3,9$ & Neopestalotiopsis & Santander, Valle del Cauca & 22.8 & 6.3 & $3.5 \mathrm{~cd}$ & $24.8(3.5-54) a b c$ & 12.3 \\
\hline $6(3)$ & Fruit, leaf & 1 & Neopestalotiopsis & Santander, Valle del Cauca & 22.5 & 6.5 & $3.4 \mathrm{de}$ & $4.6(0-7) \mathrm{c}$ & 13.4 \\
\hline $7(1)$ & Fruit & 2 & N. egyptiaca & Valle del Cauca & - & - & - & $11.8 \mathrm{c}$ & 10.8 \\
\hline $8(4)$ & Fruit, leaf & $2,3,4$ & Neopestalotiopsis & Santander, Valle del Cauca & 23.5 & 6.1 & $3.8 \mathrm{~cd}$ & $48.0(70.4-15.9) \mathrm{ac}$ & 12.5 \\
\hline $9(1)$ & Fruit & 1 & $N$. foedans & Valle del Cauca & 24.5 & 5.9 & $4.1 \mathrm{~b}$ & $11.8 \mathrm{c}$ & 10.8 \\
\hline $10(1)$ & Fruit & 8 & Neopestalotiopsis & Valle del Cauca & 21.9 & 6.8 & 3.2 ef & $11.9 \mathrm{c}$ & 11.1 \\
\hline $11(2)$ & Leaf & 1,7 & Neopestalotiopsis & Santander, Valle del Cauca & 24.3 & 8.0 & $3.0 \mathrm{f}$ & $34.0(28.7-39.3) \mathrm{ab}$ & 14.5 \\
\hline
\end{tabular}

$\mathrm{t}$ Average length (L) and width (W).

u Multilocus clades. Values in parentheses show the number of isolates in each clade.

v Infected tissue.

${ }^{\mathrm{w}}$ Nine colony morphotypes, where 1 = bright-white colony, cottony texture, intermediate mycelium density, acervuli in the middle, regular edges; $2=$ bone-white colony, velvety texture, high mycelium density, no acervuli, regular edges; 3 = bright-white colony, spiky cottony texture, low mycelium density, scattered acervuli, irregular edges; 4 = white colony, powdery spiky texture, intermediate mycelium density, acervuli in the middle, irregular edges; $5=$ white to bright-yellow colony, powdery texture, low mycelium density, scattered acervuli, regular edges; $6=$ white colony, powdery texture, low mycelium density, scattered acervuli, regular edges; 7 = white colony, powdery texture, intermediate mycelium density, abundant acervuli, regular edges; $8=$ white colony, powdery texture, low mycelium density, scattered acervuli, irregular edges; and $9=$ black colony, oily texture, low mycelium density, scattered acervuli, irregular edges.

${ }^{x}$ Length-to-width ratio (L/W). Mean difference between each group is significant at the 0.05 level; values with the same letters in a column do not differ significantly, according to the Ryan-Einot-Gabriel-Welsch (REGW) multiple-range test.

y Area under the disease-progress curve (AUDPC) average (maximum to minimum). Mean difference between each group is significant at the 0.05 level; values with the same letters in a column do not differ significantly, according to the REGW multiple-range test.

${ }^{\mathrm{z}}$ Average rate of growth (mm/day) on potato dextrose agar, with no significant differences between clades.
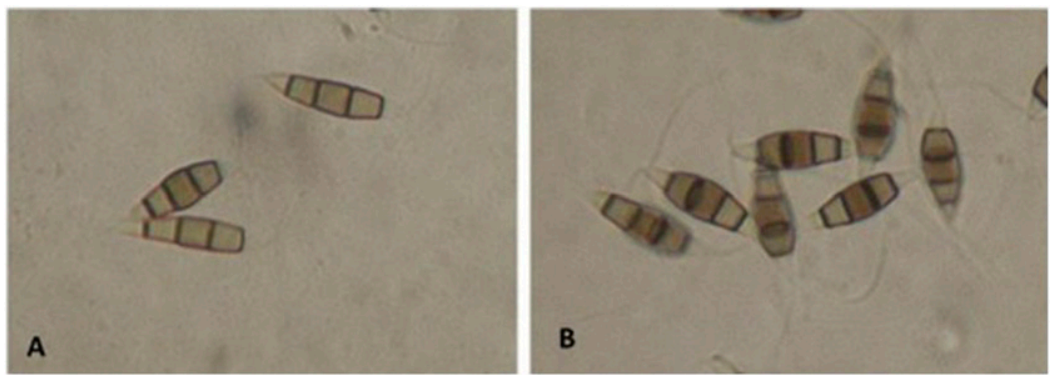

Fig. 3. Typical conidia of A, Pestalotiopsis spp., showing concolorous median cells and B, Neopestalotiopsis spp., showing versicolored median cells. (Photos taken at $\times 100$.) 
clade with two sequences of $N$. foedans; VUgu2 with two sequences that have not yet been determined; and SVsnp10, SVsnp12, SPugra3, and SV snp8 formed a clade with N. egyptiaca and VTman2, showing high sequence similarity (98.6\%) (Fig. 5).

Although no relationship was observed among the isolates based on geographical origin, most of the clades were formed by isolates from Santander and Valle de Cauca. Nevertheless, some clades and subclades consisted of grouped isolates from specific regions. For example, clade Neopestalotiopsis sp. 1 has a subclade of three isolates (SSre1, SSre2, and SSre4) that came from the same region in Santander; clade Neopestalotiopsis sp. 2 is formed by three isolates from Boyacá; and clade Neopestalotiopsis sp. 8 is formed by two isolates from Santander.

Beyond these similarities, we could not determine the species of most of the isolates because there are only a few nucleotides of difference between the sequences of the species in the genetic loci we

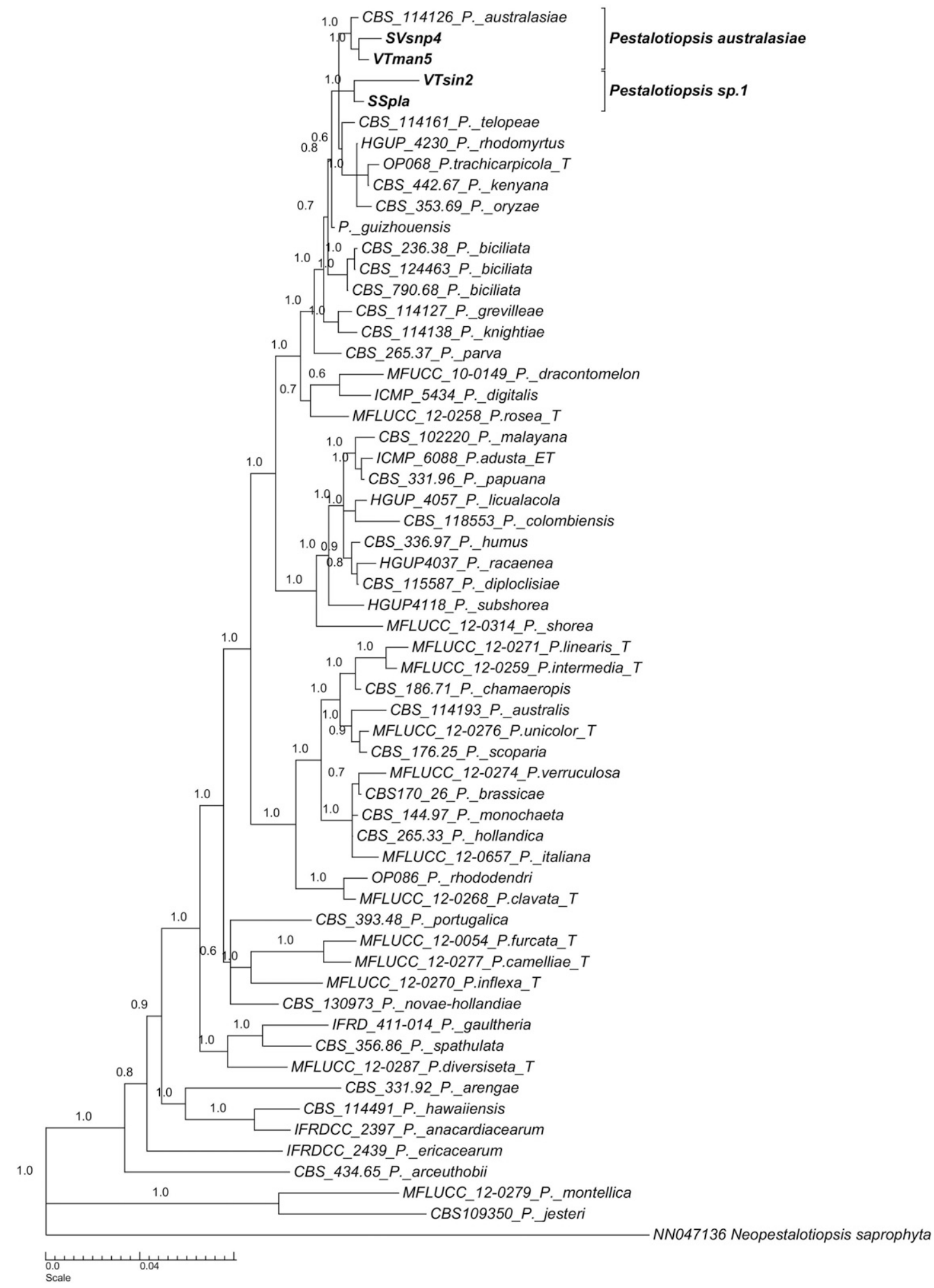

Fig. 4. Phylogenetic consensus tree based on Bayesian inference, illustrating the relationships within the Pestalotiopsis epitypified species and of isolates obtained from guava. The tree was built using concatenated sequences of the genes internal transcribed spacer, $\beta$-tubulin, and translation elongation 1 , and run for $1 \times 10^{7}$ generations, each with a separate model of DNA evolution. Neopestalotiopsis saprophyta (NN047136) was used as the outgroup. 


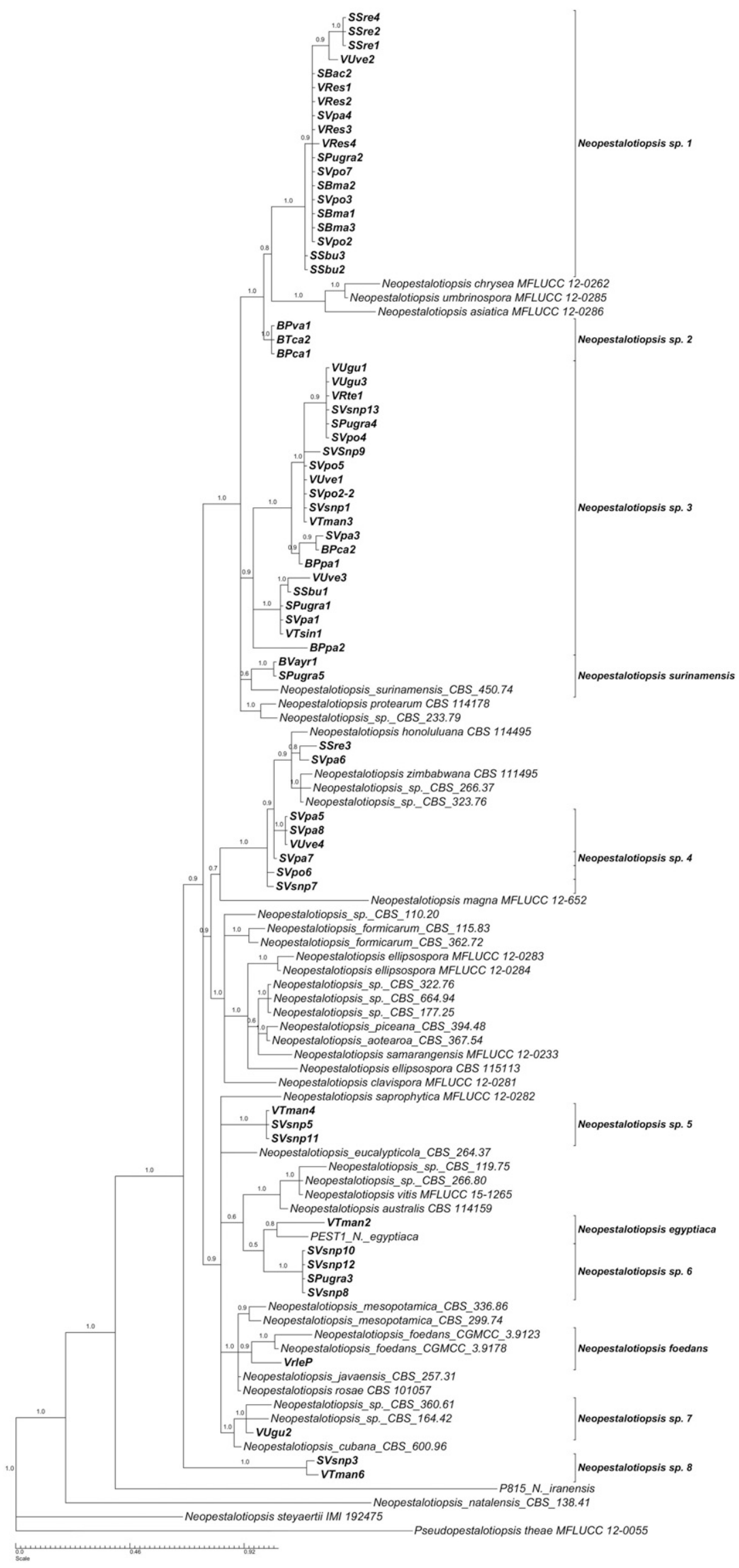

Fig. 5. Phylogenetic consensus tree based on Bayesian inference, illustrating the relationships within the Neopestalotiopsis epitypified species and of isolates obtained from guava. The tree was built using concatenated sequences of the genes internal transcribed spacer, $\beta$-tubulin, and translation elongation 1 , and run for $1 \times 10^{7}$ generations, each with a separate model of DNA evolution. Pseudopestalotiopsis theae (NN047136) was used as the outgroup. 
studied. However, both Pestalotiopsis and Neopestalotiopsis genera are clearly associated with the disease in Colombia, and the isolates showed substantial diversity.

\section{Discussion}

This is the first study documenting the genetic relationships between isolates of Neopestalotiopsis and Pestalotiopsis causing guava scab. Molecular and morphological characterization along with virulence assays demonstrated that guava scab was caused by species of more than one genus (Neopestalotiopsis and Pestalotiopsis). Selection due to geographic location was not an important factor determining genetic structure of clades. There was no correlation among origin, morphology, pathogenicity, and molecular clades based on multiple gene analysis of the isolates in Colombia (Table 1).

In this study, 77 of 81 isolates recovered from guava scab lesions were pathogenic to detached guava fruit. Virulence assays on fruit of guava cultivar Pera1 also revealed that isolates SV po5, VRes2, SVpa1, and BVayr1 were more aggressive than isolates SVsnp5, Svsnp11, and SVpa8. In addition, isolates VUgu3, VTman4, SVpa2, and BVayr2 were not pathogenic. The aggressive strains produced symptoms of guava scab on fruit tissues.

We observed the same variability in colony color (white, pale buff, pale saffron, or pale olive) and production of acervuli as Keith et al. (2006). Conidium length also was similar to that reported by Keith et al. (2006). In other studies, conidium length was reported as being as short as $15 \mu \mathrm{m}$ to as long as $35 \mu \mathrm{m}$ (Hu et al. 2007; Maharachchikumbura et al. 2013, 2014).

Most of the isolates recovered from guava scab lesions exhibited variability in the morphological characteristics evaluated. When subcultured, the isolates changed one or more colony characteristics. This was previously reported by $\mathrm{Hu}$ et al. (2007), who indicated that Pestalotiopsis spp. colony morphology is not stable under subculturing (e.g., for color, growth rate, and texture). Indeed, a single isolate was sometimes seen as having two different morphologies. Jeewon et al. (2003), Tejesvi et al. (2007), and Maharachchikumbura et al. (2011) suggest that colony morphology characteristics are plastic and variable. In contrast, conidial characteristics are more stable, especially the length, width, and color of median cells. These traits were more useful for differentiating isolates, enabling statistical analyses to separate the four Pestalotiopsis spp. evaluated (VTsin2, SSpla, SVsnp4, and VTman5) from those of the Neopestalotiopsis spp. However, it was impossible to separate or group isolates, especially those with unreliable traits. This situation made it necessary to use phylogenetic analysis to better understand the other traits and variables analyzed in our study. Maharachchikumbura et al. (2012) came to the same conclusion.

Phylogenetic analyses revealed genetic variability among the guava scab isolates, particularly those of the Neopestalotiopsis spp. The possibility of finding more than one species causing guava scab was already reported by Keith et al. (2006), who found five Pestalotiopsis spp. (P. microspora, P. clavispora, P. disseminata, P. neglecta, and Pestalotiopsis sp. GJ-1) among 23 isolates collected from different guava varieties in Hawaii. Unfortunately, none of these species is epitypified and, therefore, could not be included in our study.

Phylogenetic analysis also revealed close relationships between some reference sequences and isolates in our study. For Pestalotiopsis, isolates SVsnp4 and VTman5 were related to P. australasiae; and, for Neopestalotiopsis, BVayr1 and SPugra5 were related to $N$. surinamensis. Additionally, VTman 2 was closely related to N. egyptiaca, Vrlep was closely related to $N$. foedans, and VUgu2 was related to Neopestalotiopsis sp. CBS 360.61 and Neopestalotiopsis sp. CBS 162.42. Despite this, the expertise of a taxonomist specializing in these genera should be consulted because sequence similarity is not sufficient to identify the species. The foregoing is evident in the studies by Maharachchikumbura et al. (2012, 2014), where two species were differentiated by only one pair of nucleotides. For example, in the 2014 study, N. honoluluana and N. zimbabwana differed by only six nucleotides but were defined as two species. In contrast, in the 2012 study, one of the $N$. foedans isolates differed by six nucleotides but was considered to be the same species as the other two $N$. foedans isolates evaluated.
This situation shows the importance of combining morphological traits with phylogenetic analysis when determining a new species. In our study, we could not reach this level of depth, because our objective was phytopathological rather than taxonomic. Nevertheless, our data showed that the guava scab in Colombia is caused by a complex of species of the genera Pestalotiopsis and Neopestalotiopsis. These results agree with those of Keith et al. (2006), taking into account that, in their study, the Pestalotiopsis and Neopestalotiopsis genera were classified as one genus.

The isolates belonging to 6 of the 11 clades (Neopestalotiopsis spp. 1, 2, 3, 5, 6, and 11) could be defined as new species (S. S. N. Maharachchikumbura, personal communication). It is even possible that some clades may include more than one species; for example, clades Neopestalotiopsis spp. 1, 3, and 5 (Fig. 5). Our findings represent an important contribution to the etiology and epidemiology of guava scab in Colombia. We provide evidence for diversity in both the Neopestalotiopsis and Pestalotiopsis spp. associated with the disease in guava. Our study facilitates the development of future epidemiological research in guava and other crops. It offers information relevant to the design of management strategies, such as appropriate chemistries and crop rotation, and to the evaluation of resistance in Psidium germplasm to the different Neopestalotiopsis and Pestalotiopsis isolates.

\section{Acknowledgments}

This work was financed by the OPEC Fund for International Development (OFID) (2012 to 2013). We thank N. Ramírez, who participated in field collection; $\mathrm{N}$. Vargas and D. Vargas for managing and collaborating with field collections in Vélez; J. Cuasquer for data analysis; and L. Gañan, G. Ceballos, J. M. Pardo, M. Latorre, Z. Zamora, V. Domínguez, and A. Soler for their assistance.

\section{Literature Cited}

Ariyawansa, H. A., Hyde, K. D., Jayasiri, S. C., Buyck, B., Chethana, K. W. T., Dai, D. Q., Dai, Y. C., Daranagama, D. A., Jayawardena, R. S., Lücking, R., Ghobad-Nejhad, M., Niskanen, T., Thambugala, K. M., Voigt, K., Zhao, R. L., Li, G.-J., Doilom, M., Boonmee, S., Yang, Z. L., Cai, Q., Cui, Y.-Y., Bahkali, A. H., Chen, J., Cui, B. K., Chen, J. J., Dayarathne, M. C., Dissanayake, A. J., Ekanayaka, A. H., Hashimoto, A., Hongsanan, S., Jones, E. B. G., Larsson, E., Li, W. J., Li, Q.-R., Liu, J. K., Luo, Z. L., Maharachchikumbura, S. S. N., Mapook, A., McKenzie, E. H. C. Norphanphoun, C., Konta, S., Pang, K. L., Perera, R. H., Phookamsak, R., Phukhamsakda, C., Pinruan, U., Randrianjohany, E., Singtripop, C., Tanaka, K., Tian, C. M., Tibpromma, S., Abdel-Wahab, M. A., Wanasinghe, D. N., Wijayawardene, N. N., Zhang, J.-F., Zhang, H., Abdel-Aziz, F. A., Wedin, M., Westberg, M., Ammirati, J. F., Bulgakov, T. S., Lima, D. X., Callaghan, T. M., Callac, P., Chang, C.-H., Coca, L. F., Dal-Forno, M., Dollhofer, V., Fliegerová, K., Greiner, K., Griffith, G. W., Ho, H.-M., Hofstetter, V., Jeewon, R., Kang, J. C., Wen, T.-C., Kirk, P. M., Kytövuori, I., Lawrey, J. D., Xing, J., Li, H., Liu, Z. Y., Liu, X. Z., Liimatainen, K., Lumbsch, H. T., Matsumura, M., Moncada, B., Nuankaew, S., Parnmen, S., de Azevedo Santiago, A. L. C. M., Sommai, S., Song, Y., de Souza, C. A. F., de SouzaMotta, C. M., Su, H. Y., Suetrong, S., Wang, Y., Wei, S.-F., Wen, T. C., Yuan, H. S., Zhou, L. W., Réblová, M., Fournier, J., Camporesi, E., Luangsa-ard, J. J., Tasanathai, K., Khonsanit, A., Thanakitpipattana, D., Somrithipol, S., Diederich, P., Millanes, A. M., Common, R. S., Stadler, M., Yan, J. Y., Li, X., Lee, H. W., Nguyen, T. T. T., Lee, H. B., Battistin, E., Marsico, O., Vizzini, A., Vila, J., Ercole, E., Eberhardt, U., Simonini, G., Wen, H.-A., Chen, X.-H., Miettinen, O., Spirin, V., and Hernawati. 2015. Fungal diversity notes 111-252-Taxonomic and phylogenetic contributions to fungal taxa. Fungal Divers. 75:27-274.

Buriticá-Cespedes, P. E. 1999. Directorio de patógenos y enfermedades de las plantas de importancia económica en Colombia. Universidad Nacional de Colombia, Bogotá.

De Notaris, G. 1839. Micromycetes italiei Dec. II. Mere R. Acad. Sci. Torino II 3:80-81.

Egger, K. N. 1995. Molecular analysis of ectomycorrhizal fungal communities. Can. J. Bot. 73:1415-1422.

Farfán, P. D., Insuasty, O., and Casierra, F. 2006. Distribución espacio temporal y daño ocasionado por Pestalotia spp. en frutos de guayaba. Rev. Corpoica 7:89-98.

Glass, N. L., and Donaldson, G. C. 1995. Development of primer sets designed for use with the PCR to amplify conserved genes from filamentous ascomycetes. Appl. Environ. Microbiol. 61:1323-1330.

Gramaje, D., Armengol, J., Mohammadi, H., Banihashemi, Z., and Mostert, L. 2009. Novel Phaeoacremonium species associated with Petri disease and esca of grapevines in Iran and Spain. Mycologia 101:920-929.

Griffiths, D. A., and Swart, H. J. 1974a. Conidial structure in two species of Pestalotiopsis. Trans. Br. Mycol. Soc. 62:295-304, IN14-IN20. 
Griffiths, D. A., and Swart, H. J. 1974b. Conidial structure in Pestalotia pezizoides. Trans. Br. Mycol. Soc. 63:169-173, IN26-IN27.

Gutiérrez, R. M. P., Mitchell, S., and Vargas, S. R. 2008. Psidium guajava: A review of its traditional uses, phytochemistry and pharmacology. J. Ethnopharmacol. 117:1-27.

Hu, H. L., Jeewon, R., Zhou, D. Q., Zhou, T. X., and Hyde, K. D. 2007. Phylogenetic diversity of endophytic Pestalotiopsis species in Pinus armandii and Ribes spp.: Evidence from rDNA and $\beta$-tubulin gene phylogenies. Fungal Divers. 24:1-22.

Jayawardena, R. S., Liu, M., Maharachchikumbura, S. S. N., Zhang, W., Xing, Q., Hyde, K. D., Nilthong, S., Li, X. H., and Yan, J. Y. 2016. Neopestalotiopsis vitis sp. nov., causing grapevine leaf spot in China. Phytotaxa 258:63-74.

Jeewon, R., Liew, E. C., Simpson, J. A., Hodgkiss, J., and Hyde, K. D. 2003. Phylogenetic significance of morphological characters in the taxonomy of Pestalotiopsis species. Mol. Phylogenet. Evol. 27:372-383.

Keith, L. M., Velásquez, M. E., and Zee, F. T. 2006. Identification and characterization of Pestalotiopsis spp. causing scab disease of guava, Psidium guajava, in Hawaii. Plant Dis. 90:16-23.

Kumar, S., Stecher, G., Peterson, D., and Tamura, K. 2012. MEGA-CC: Computing core of molecular evolutionary genetics analysis program for automated and iterative data analysis. Bioinformatics 28:2685-2686.

Liu, J. K., Hyde, K. D., Jones, E. B. G., Ariyawansa, H. A., Bhat, D. J., Boonmee, S., Maharachchikumbura, S. S. N., McKenzie, E. H. C., Phookamsak, R., Phukhamsakda, C., Shenoy, B. D., Abdel-Wahab, M. A., Buyck, B., Chen, J., Chethana, K. W. T., Singtripop, C., Dai, D. Q., Dai, Y. C., Daranagama, D. A., Dissanayake, A. J., Doilom, M. D’Souza, M. J., Fan, X. L., Goonasekara, I. D., Hirayama, K., Hongsanan, S., Jayasiri, S. C., Jayawardena, R. S., Karunarathna, S. C., Li, W. J., Mapook, A., Norphanphoun, C., Pang, K. L., wPerera, R. H., Peršoh, D., Pinruan, U., Senanayake, I. C., Somrithipol, S., Suetrong, S., Tanaka, K., Thambugala, K. M., Tian, Q., Tibpromma, S., Udayanga, D., Wijayawardene, N. N., Wanasinghe, D., Wisitrassameewong, K., Zeng, X. Y., Abdel-Aziz, F. A., Adamčík, S., Bahkali, A. H., Boonyuen, N., Bulgakov, T., Callac, P., Chomnunti, P., Greiner, K., Hashimoto, A., Hofstetter, V., Kang, J. C., Lewis, D., Li, X. H., Liu, X. Z., Liu, Z. Y., Matsumura, M., Mortimer, P. E., Rambold, G., Randrianjohany, E., Sato, G., Sri-Indrasutdhi, V., Tian, C. M., Verbeken, A., von Brackel, W., Wang, Y., Wen, T. C., Xu, J. C., Yan, J. Y., Zhao, R. L., and Camporesi, E. 2015. Fungal diversity notes 1-110: Taxonomic and phylogenetic contributions to fungal species. Fungal Divers. 72: 1-197.

Maharachchikumbura, S. S. N., Guo, L. D., Cai, L., Chukeatirote, E., Wu, W. P., Sun, X., Crous, P. W., Bhat, D. J., McKenzie, E. H. C., Bahkali, A. H., and Hyde, K. D. 2012. A multi-locus backbone tree for Pestalotiopsis, with a polyphasic characterization of 14 new species. Fungal Divers. 56:95-129.

Maharachchikumbura, S. S. N., Guo, L. D., Chukeatirote, E., Bahkali, A. H., and Hyde, K. D. 2011. Pestalotiopsis-Morphology, phylogeny, biochemistry and diversity. Fungal Divers. 50:167-187.

Maharachchikumbura, S. S. N., Hyde, K. D., Groenewald, J. Z., Xu, J., and Crous, P. W. 2014. Pestalotiopsis revisited. Stud. Mycol. 79:121-186.
Maharachchikumbura, S. S. N., Zhang, Y., Wang, Y., and Hyde, K. D. 2013. Pestalotiopsis anacardiacearum sp. nov. (Amphisphaeriaceae) has an intricate relationship with Penicillaria jocosatrix the mango tip borer. Phytotaxa 99: 49-57.

Melgarejo, L. M., Romero, H. M., Insuasty, O., Hernández, M. S., Fernández Trujillo, J. P., Solarte, M. E., Osorio, C., Morales, A. L., Barbosa, H., Jiménez, A., Forero, D. P., Restrepo, L. P., Parada, F., Camacho, M. I. Espinal, M., García, J., Jiménez, L., Silva, K., Olaya, J., and Castro, H. 2010 Desarrollo de Productos Funcionales Promisorios a Partir de la Guayaba (Psidium guajava L.) para el Fortalecimiento de la Cadena Productiva. Universidad Nacional de Colombia, Bogotá. Online publication. http://www. bdigital.unal.edu.co/8536/\#sthash.TfUEv4A0.dpuf

Morera-Montoya, R., and Blanco-Metzler, H. 2009. Microorganismos asociados a frutos embolsados de guayaba taiwanesa variedad Tai Kuo1. Agron. Mesoam. 20:339-349.

Pachanawan, A., Phumkhachorn, P., and Rattanachaikunsopon, P. 2008. Potential of Psidium guajava supplemented fish diets in controlling Aeromonas hydrophila infection in tilapia (Oreochromis niloticus). J. Biosci. Bioeng. 106:419-424.

Posada, D. 2008. jModelTest: Phylogenetic model averaging. Mol. Biol. Evol. 25:1253-1256.

Rehner, S. A. 2001. Primers for elongation factor 1-alpha (EF1-alpha). http:// www2.clarku.edu/faculty/dhibbett/Protocols_Folder/Primers/Primers.pdf

Rodríguez-Borray, G., and Rangel-Moreno, C. 2005. Estudio del Sistema Agroalimentario Localizado, SIAL, de la Concentración de Fábricas de Bocadillo de Guayaba en las Provincias de Vélez y Ricaurte en Colombia. CORPOICA, Bogotá, Columbia.

Romero-Frías, A., Simões-Bento, J. M., and Osorio, C. 2015. Chemical signaling between guava (Psidium guajava L., Myrtaceae) and the guava weevil (Conotrachelus psidii Marshall). Rev. Fac. Cienc. Econ. Invest. Reflexion 11:102-113.

Ronquist, F., Teslenko, M., van der Mark, P., Ayres, D., Darling, A., Höhna, S., Larget, B., Liu, L., Suchard, M., and Huelsenbeck, J. P. 2012. MrBayes v. 3.2: Efficient Bayesian phylogenetic inference and model choice across a large model space. Syst. Biol. 61:539-542.

Steyaert, R. L. 1955. Pestalotia, Pestalotiopsis et Truncatella. Bull. Jard. Bot Brux. 25:191-199.

Sutton, B. C. 1980. The Coelomycetes. Fungi Imperfecti with Pycnidia, Acervuli and Stromata. Commonwealth Mycological Institute, Kew, Surrey, U.K

Tejesvi, M. V., Kini, K. R., Prakash, H. S., Subbiah, V., and Shetty, H. S. 2007 Genetic diversity and antifungal activity of species of Pestalotiopsis isolated as endophytes from medicinal plants. Fungal Divers. 24:37-54.

White, T. J., Bruns, T., Lee, S., and Tailor, J. 1990. Amplification and direct sequencing of fungal ribosomal RNA genes for phylogenetics. Pages 315-322 in: PCR Protocols: A Guide to Methods and Applications. M. A. Innis, D. H. Gelfand, J. J. Snisky, and J. J. White, eds. Academic Press, San Diego, CA. 